\title{
A plastid DNA phylogeny of Dasymaschalon (Annonaceae) and allied genera: Evidence for generic non-monophyly and the parallel evolutionary loss of inner petals
}

\author{
Jing Wang, ${ }^{1}$ Daniel C. Thomas, ${ }^{1}$ Yvonne C.F. Su, ${ }^{1,2}$ Svenja Meinke, ${ }^{3}$ Lars W. Chatrou ${ }^{4}$ \\ \& Richard M.K. Saunders ${ }^{1}$ \\ 1 School of Biological Sciences, The University of Hong Kong, Pokfulam Road, Hong Kong, P.R. China \\ 2 Current address: Duke-NUS Graduate Medical School Singapore, 8 College Road, Singapore 169857 \\ 3 Netherlands Centre for Biodiversity Naturalis (section NHN), Leiden University, P.O. Box 9514, 2300 RA, Leiden, The Netherlands \\ 4 Wageningen University, Biosystematics Group, Droevendaalsesteeg 1, 6708 PB Wageningen, The Netherlands \\ Jing Wang and Daniel C. Thomas contributed equally to this work. \\ Authors for correspondence: Daniel C.Thomas,dthomas@hku.hk;RichardM.K.Saunders, saunders@hku.hk
}

\begin{abstract}
Dasymaschalon and the closely related genera Desmos, Friesodielsia and Monanthotaxis together comprise ca. 170 species of trees, shrubs and woody climbers distributed in tropical Africa and tropical Asia. These genera form the desmoid clade, which, because of the presence of diverse flower and fruit syndromes including different types of pollination chambers and moniliform monocarps, offers an opportunity to investigate potentially ecologically significant shifts in flower and fruit characters. Despite its morphological diversity, however, generic delimitation within the desmoid clade is problematic and the intergeneric relationships of the constituent genera are only poorly understood. Bayesian, maximum likelihood and maximum parsimony analyses of plastid DNA sequence data (matK, psbA-trnH, ndhF, rbcL, trnL-F; ca. $5.4 \mathrm{~kb} ; 52$ taxa) were used to clarify phylogenetic relationships within the desmoid clade. The evolution and taxonomic utility of selected fruit and flower characters was investigated with likelihood and parsimony ancestral character reconstructions. The results indicate problems in the current delimitations of Dasymaschalon and Friesodielsia. Friesodielsia as currently circumscribed is polyphyletic, with African Friesodielsia species allied to the African genus Monanthotaxis, and only distantly related to Asian representatives. The majority of Dasymaschalon species form a strongly supported clade, but three species are more closely related to Asian species of Friesodielsia. Ancestral character reconstructions indicate that seed number and monocarp shape are of limited value in generic circumscriptions, and that the three-petalled corolla characteristic of Dasymaschalon evolved independently twice within the desmoid clade. Disruptions to homeotic gene expression or strong selective pressure for a partial enclosure of the mature stamens and carpels by the corolla are hypothesised to underlie the parallel evolution of pollination chambers formed by outer petal homologues subsequent to inner petal loss.
\end{abstract}

Keywords Annonaceae; character evolution; Dasymaschalon; Friesodielsia; flower morphology; phylogeny

\begin{abstract}
Supplementary Material The alignment files are available in the Supplementary Data section of the online version of this
\end{abstract} article (http://www.ingentaconnect.com/content/iapt/tax).

\section{口INTRODUCTION}

The genus Dasymaschalon (Hook.f. \& Thomson) Dalla Torre \& Harms (Fig. 1A-C, H, I) comprises ca. 27 species of small trees and shrubs (except D. grandiflorum Jing Wang, Chalermglin \& R.M.K. Saunders, which is a climber), with a centre of diversity in continental Southeast Asia (Wang \& al., 2009). Molecular phylogenetic studies indicate that Dasymaschalon is part of a well-supported subclade of tribe Uvarieae in Annonaceae subfam. Annonoideae (the desmoid clade), which also includes the genera Desmos Lour. (Fig. 1D, E, J), Friesodielsia Steenis (Fig. 1F, K) and Monanthotaxis Baill. (Fig. 1G, L) (Richardson \& al., 2004; Couvreur \& al., 2011; Chatrou \& al., 2012). This is corroborated by palynological data, which shows that these genera have a putatively synapomorphic inaperturate pollen type with a thin exine and echinate ornamentation (Walker, 1971; Le Thomas, 1980,
1981; Bygrave, 2000; Doyle \& Le Thomas, 2012). The majority of species within the desmoid clade are furthermore characterized by monocarps with distinct constrictions between neighbouring seeds and glaucous abaxial leaf surfaces. Molecular phylogenetic studies by Richardson \& al. (2004) and Couvreur $\&$ al. (2011) indicate a close relationship of Dasymaschalon and Desmos with Asian species of Friesodielsia, while African Friesodielsia species were inferred to be more closely related to the African genus Monanthotaxis. These studies did not result in nomenclatural changes, however, because of limited species sampling (less than $5 \%$ of the ca. 170 species in the desmoid clade), highlighting the need for molecular phylogenetic studies based on a denser taxon sampling.

Flower morphology readily distinguishes Dasymaschalon from closely related genera. Unlike those of the vast majority of Annonaceae, the flowers of Dasymaschalon only have one whorl of three petals (Fig. 1A-C); these petals are alternately 
positioned relative to the sepals and are homologous with the outer petals of other Annonaceae species. The petals converge apically and the broad petal margins adhere between contiguous petals, forming a dome over the reproductive organs (Fig. 1B), often with small basal apertures between the petals (Fig. 1A). The enclosed floral chamber is likely to function in the same way as the pollination chambers formed by the inner petals in many other Annonaceae genera (Saunders, 2010, 2012). Another conspicuous character in Dasymaschalon is the structure of the monocarps, which, if multi-seeded, show distinct constrictions between neighbouring seeds (Fig. 1H). Such moniliform monocarps are unusual in Annonaceae, but are also present in the closely related genus Desmos (Fig. 1J), which consists of 26 species (Rainer \& Chatrou, 2006) of woody climbers distributed throughout Southeast Asia and northern Australia. The similarities between Dasymaschalon and Desmos with regard to fruit morphology have caused considerable difficulty in identification in the absence of flowers, and, in combination with similarities in stamen and carpel morphology, have led some taxonomists to adopt a broader delimitation of Desmos, inclusive of Dasymaschalon (Sinclair, 1955; Maxwell, 1989; Li, 1993). Unlike those of Dasymaschalon, however, Desmos flowers have two whorls of three petals, and the inner petals are basally constricted around the reproductive organs, forming a partially enclosed pollination chamber, with the apical parts of the petals splayed outwards (Fig. 1D, E). Dasymaschalon furthermore mainly comprises small trees, whereas Desmos species are woody climbers. Based on these differences in growth habit and floral morphology most authors have treated Dasymaschalon and Desmos as distinct genera (Wang \& al., 2009, and references therein).

The present study was initially intended to clarify the phylogenetic relationships of Dasymaschalon within the desmoid clade. Preliminary phylogenetic analyses of DNA sequence data, however, surprisingly retrieved different species of the genus within different clades, indicating a close relationship of some Dasymaschalon species with Asian species of Friesodielsia. There are thus several open questions with regard to the phylogenetic relationships and systematics of Dasymaschalon and the other constituent genera of the desmoid clade, which require clarification: (1) Is Dasymaschalon in its current circumscription monophyletic, and does the single petal whorl characteristic of the genus represent a synapomorphy of the ca. 27 species placed in Dasymaschalon? (2) Is Friesodielsia polyphyletic as indicated in previous molecular phylogenetic studies (Richardson \& al., 2004; Couvreur \& al., 2011), and, if so, what are the phylogenetic affinities of its segregates? (3)
What are the intergeneric relationships within the desmoid clade? Sequence data of five chloroplast DNA regions ( $m a t K$, $n d h F, p s b A$-trnH spacer, $r b c L, \operatorname{trn} L-F)$ of 10 outgroup species and 42 species of the constituent genera of the desmoid clade were analysed to address these questions. Selected fruit and flower characters were mapped onto the phylogeny to determine their utility for taxon circumscription, and to gain insights into the evolution of flowers and fruits in Dasymaschalon and allied genera.

\section{MATERIALS AND METHODS}

Taxon sampling. - The dataset comprised 42 species of the desmoid clade, including the type species of the four constituent genera (Dasymaschalon dasymaschalum (Blume) I.M. Turner, Desmos cochinchinensis Lour., Friesodielsia cuneiformis (Blume) Steenis, Monanthotaxis congoensis Baill.). Sequence data were obtained for 21 Dasymaschalon accessions (representing ca. $78 \%$ of the species diversity of the genus), eight accessions of Desmos (ca. 31\% of species), six accessions of Friesodielsia (ca. 12\% of species), and seven species of Monanthotaxis (ca. 13\% of species). Six closely related taxa of tribe Uvarieae (Fissistigma polyanthoides Merr., Mitrella kentii Miq., Sphaerocoryne gracilis (Engl. \& Diels) Verdc., Sphaerocoryne sp., Toussaintia orientalis Verdc., Uvaria lucida Boj. ex Sweet), and four species of the more distantly related tribe Monodoreae (Hexalobus salicifolius Engl., Isolona campanulata Engl. \& Diels, Sanrafaelia ruffonammari Verdc., Uvariodendron molundense (Diels) R.E. Fr.) were selected as outgroup based on previous studies (Zhou \& al., 2009, 2010; Couvreur \& al., 2011). Existing DNA sequences were downloaded from the nucleotide database of the National Centre for Biotechnology Information (http://www.ncbi.nlm.nih.gov), and 202 sequences were newly generated for this study (voucher information and GenBank accession numbers are given in the Appendix).

DNA extraction, amplification and sequencing. Genomic DNA was extracted from silica-dried or herbarium material using the innuPrep Plant DNA Kit (Analytika Jena, Jena, Germany) following the manufacturer's instructions, or using a modified cetyl trimethyl ammonium bromide (CTAB) method (Doyle \& Doyle, 1987; Erkens \& al., 2008; Su \& al., 2008). For amplification each $25 \mu \mathrm{l}$ PCR contained $12.55 \mu 1$ of $\mathrm{ddH}_{2} \mathrm{O}, 5 \mu \mathrm{l}$ of $10 \times$ reaction buffer, $3 \mu \mathrm{l}$ of $\mathrm{MgCl}_{2}(25 \mathrm{mM})$, $0.5 \mu \mathrm{l}$ dNTPs (10 mM each), $0.75 \mu \mathrm{l}$ of each forward and reverse primer $(10 \mu \mathrm{M}), 1.25 \mu \mathrm{l}$ bovine serum albumin (BSA,

Fig. 1. Flower and fruit morphology in the desmoid clade (Dasymaschalon, Desmos, Friesodielsia, Monanthotaxis). A, Dasymaschalon lomentaceum flower, showing the apically connivent petals with basal aperture; B, Dasymaschalon trichophorum flower, with proximal petal removed to show pollination chamber and pollinators (Endaenidius sp., Curculionidae, Coleoptera), scale bar $=5 \mathrm{~mm}$; $\mathbf{C}$, Dasymaschalon filipes flowers, showing the long, narrow petals; D, Desmos chinensis flower; E, Desmos chinensis flower, showing basal constrictions of the three inner petals around the reproductive organs; F, Friesodielsia desmoides flower, showing apically connivent inner petals and free outer petals; G, Monanthotaxis schweinfurthii flower; H, Dasymaschalon dasymaschalum fruit with multi-seeded monocarps; I, Dasymaschalon filipes fruit with 1-2 seeds per monocarp; J, Desmos chinensis fruit with multi-seeded monocarps; K, Friesodielsia kingii fruit with single-seeded monocarps; L, Monanthotaxis boivinii fruit with 1-2 seeds per monocarp. - Photographs: A, Richard Saunders; B, D, E, J, Pang Chun Chiu; C, F, H, I, K, Piya Chalermglin (reprinted with permission from Chalermglin, 2001); G, Thomas L.P. Couvreur; L, Lars W. Chatrou. 


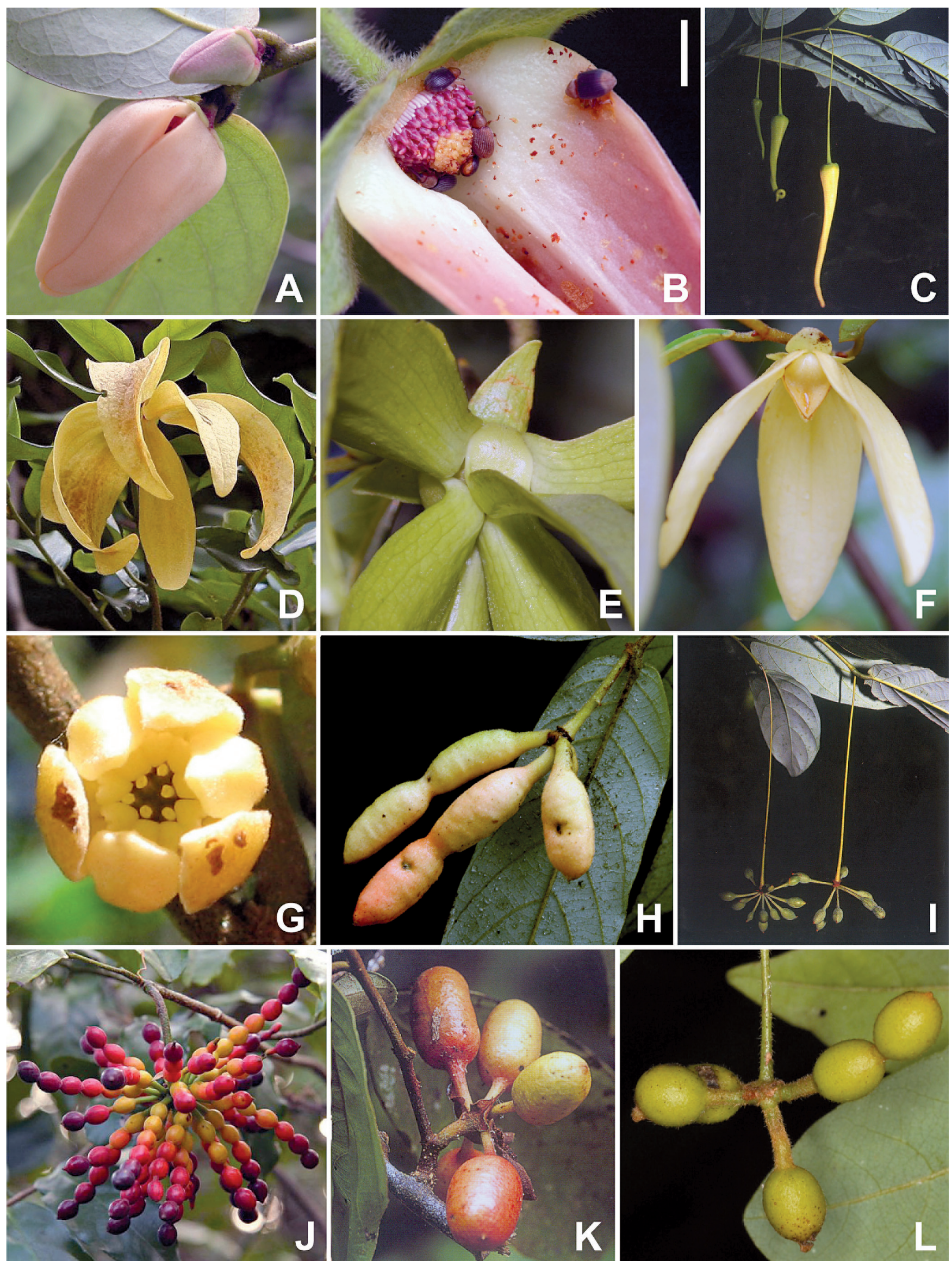


$10 \mathrm{mg} / \mathrm{ml}$ ), $0.2 \mu \mathrm{l}$ of Flexitaq DNA polymerase (Promega, Madison, Wisconsin, U.S.A.) and $1 \mu \mathrm{l}$ of DNA template. Primers and protocols for the amplification of the matK, psbA-trnH, $\operatorname{trn} L-F$ and $r b c L$ regions were the same as in Su \& al. (2008). Primers designed by Olmstead \& Sweere (1994) and Erkens (2007) as well as several newly designed primers were used for amplification of the $n d h F$ region (Table 1). The $n d h F$ amplification profile included template denaturation at $80^{\circ} \mathrm{C}$ for $5 \mathrm{~min}$ followed by 32 cycles of denaturation at $95^{\circ} \mathrm{C}$ for $1 \mathrm{~min}$, primer annealing at $50^{\circ} \mathrm{C}$ for $1 \mathrm{~min}$, followed by a ramp of $0.3^{\circ} \mathrm{C} / \mathrm{s}$ to $65^{\circ} \mathrm{C}$, and primer extension at $65^{\circ} \mathrm{C}$ for $4 \mathrm{~min}$; followed by a final extension step at $65^{\circ} \mathrm{C}$ for $5 \mathrm{~min}$.

Amplifications using DNA extracted from herbarium specimens frequently required several internal primer pairs (Su \& al., 2008; Table 1), and for some samples amplification failed or only partial sequences were generated (see Table 2 for percentages of missing data in each DNA region alignment). Amplification products were visualized under UV light after electrophoretic separation on a $1 \%$ agarose TBE gel stained with SYBR Safe gel stain (Invitrogen, Carlsbad, California, U.S.A.). PCR product purification and amplification using the BigDye Terminator Cycle Sequencing Kit (Applied Biosystems, Foster City, California, U.S.A.), and sequencing run on an
AB 3730 DNA Analyser (Applied Biosystems) were performed by BGI (Hong Kong, P.R. China).

Alignment and phylogenetic analyses. - Sequences were assembled and edited using Geneious v.5.4.3 (Drummond $\&$ al., 2010). The sequences were pre-aligned using the MAFFT (Katoh \& al., 2009) plugin in Geneious using the automatic algorithm selection and default settings, and subsequently manually checked and optimized. A 13 base pair (bp) inversion was identified in the $p s b A$-trn $H$ region of five species (Dasymaschalon filipes (Ridl.) Bân, Isolona campanulata, Monanthotaxis congoensis, Uvariodendron molundense, Uvaria lucida). These species are only distantly related in phylogenetic trees resulting from the analysis of the cpDNA nucleotide data, indicating the homoplasy of this inversion (see Pirie \& al., 2006). This inversion and one mutational hotspot in the $p s b A$-trnH spacer, collectively ca. $1.2 \%$ of the aligned positions, were excluded from the analyses because of problematic homology assessment.

Bayesian and maximum likelihood (ML) phylogenetic reconstructions were performed using the NSF teragrid applications of MrBayes v.3.1.2 (Huelsenbeck \& Ronquist, 2001; Ronquist \& Huelsenbeck, 2003) and RAxML v.7.2.8 (Stamatakis, 2006), respectively, provided by the CIPRES Science Gateway

Table 1. Primers used for the amplification of the $n d h F$ cpDNA region.

\begin{tabular}{llll}
\hline Primer name & Primer pair & Primer sequence $\left(5^{\prime}-3^{\prime}\right)$ & Source \\
\hline $1 \mathrm{~F}$ & 1,3 & ATGGAACAKACATATSAATATGC & Olmstead \& Sweere, 1994 \\
$972 \mathrm{R}$ & 1 & CATCATATAACCCAATTGAGAC & Olmstead \& Sweere, 1994 \\
$972 \mathrm{~F}$ & 2,6 & GTCTCAATTGGGTTATATGATG & Olmstead \& Sweere, 1994 \\
$2110 \mathrm{R}$ & 2,8 & CCCCCTAYATATTTGATACCTTCTCC & Olmstead \& Sweere, 1994 \\
$584 \mathrm{R}$ & 3 & CCTAAGATTCCTAATAATAAACCA & This study \\
$451 \mathrm{~F}$ & 4 & TGGGAACTAGTGGGAATGTGCTCG & This study \\
$689 \mathrm{R}$ & 4 & GGCATCAGGCAACCATACATGAAG & Erkens, 2007 \\
$561 \mathrm{~F}$ & 5 & TGGTTTATTATTAGGAATCTTAGG & This study \\
$1025 \mathrm{R}$ & 5 & GCAGCTCGATAAGAACCTATACCTGG & This study \\
$1321 \mathrm{R}$ & 6 & ATCCTGCCGCGGAACAAGCT & This study \\
$1216 \mathrm{~F}$ & 7 & TGTGGTATTCCGCCCCTTGCT & This study \\
$1621 \mathrm{R}$ & 7 & TGTCTGACTCATGGGGATATGTGG & This study \\
1598F & 8 & CCGCATATCCCCATGAGTCGGACA & This study \\
\hline
\end{tabular}

Table 2. Descriptive statistics of analysed plastid DNA sequence data matrices.

\begin{tabular}{|c|c|c|c|c|c|c|c|}
\hline \multirow[b]{2}{*}{ DNA region } & \multirow{2}{*}{$\begin{array}{l}\text { Aligned } \\
\text { length }\end{array}$} & \multirow{2}{*}{$\begin{array}{l}\text { Excluded } \\
\text { sites }\end{array}$} & \multirow{2}{*}{$\begin{array}{l}\% \text { Missing } \\
\text { data }\end{array}$} & \multicolumn{2}{|c|}{ Variable characters $(\%)$} & \multicolumn{2}{|c|}{ Parsimony-informative characters $(\%)$} \\
\hline & & & & Entire dataset & Ingroup & Entire dataset & Ingroup \\
\hline $\operatorname{mat} K$ & 780 & 0 & 3.9 & $123(15.8)$ & $56(7.2)$ & $55(7.1)$ & $34(4.4)$ \\
\hline$p s b A-t r n H$ & 410 & 67 & 5.0 & $114(27.8)$ & $69(16.8)$ & $60(14.6)$ & $36(8.8)$ \\
\hline$r b c L$ & 1342 & 0 & 5.3 & $109(8.1)$ & $54(4.0)$ & $45(3.4)$ & $27(2.0)$ \\
\hline Combined data & 5489 & 67 & 12.5 & $1005(18.3)$ & $461(8.4)$ & $458(8.3)$ & $238(4.3)$ \\
\hline
\end{tabular}


(Miller \& al., 2010). Maximum parsimony (MP) analyses were performed in PAUP* v.4.0b10 (Swofford, 2002).

For the Bayesian analyses three partitioning schemes were used: (1) five partitions based on DNA region identity; (2) two partitions based on coding region (matK, $n d h F, r b c L$, and the tRNA coding parts of the $\operatorname{trn} L-F$ region) and non-coding region ( $p s b A$-trnH spacer, $\operatorname{trn} L$-trnF spacer, $\operatorname{trn} L$ intron) identity; and (3) the cpDNA regions concatenated and analysed without partitioning. Best-fitting nucleotide substitution models for the concatenated matrix and each nucleotide sequence partition were determined with MrModeltest v.2 (Nylander, 2004) using the Akaike information criterion (AIC). Overall performance of analyses of unpartitioned and partitioned nucleotide datasets was assessed with Bayes factor comparison implemented in Tracer v.1.5 (Rambaut \& Drummond, 2009), which is based on marginal likelihood estimates using the method by Newton \& Raftery (1994) with modifications by Suchard \& al. (2001). The criterion of $2 \ln$ Bayes factor of $\geq 10$ was used as a benchmark indicating very strong evidence in favour of one strategy over another (Kass \& Raftery, 1995). Four independent Metropolis-coupled Markov chain Monte Carlo (MCMC) analyses were run. Each search used three incrementally heated and one cold Markov chain, a temperature parameter setting of 0.18 , and was run for $10^{7}$ generations and sampled every 1000 generations. The parameters for character state frequencies, the substitution rates of the nucleotide substitution models, and the rate variation among sites were unlinked across partitions. Preliminary analyses resulted in nonsensically high estimates of the rate multiplier of some partitions, which has been shown to be a common phenomenon in partitioned analyses using MrBayes (Brown \& al., 2010; Marshall, 2010). Following recommendations by Marshall (2010), the mean branch length prior was set from the default mean (0.1) to 0.01 , which reduces the likelihood of stochastic entrapment in local tree length optima, and resulted in good convergence and realistic rate multiplier estimates. Convergence was assessed by using the standard deviation of split frequencies as convergence index with values $<0.005$ interpreted as indicating good convergence. Tracer v.1.5 was used to determine whether the MCMC parameter samples were drawn from a stationary, unimodal distribution, and whether adequate effective sample sizes for each parameter (ESS > 200) were reached. Convergence of posterior probabilities of splits within and between different runs was visually checked using the Cumulative and Compare functions in AWTY (Nylander \& al., 2008). The initial 25\% of samples of each MCMC run were discarded as burn-in, and the post-burnin samples were summarized as a $50 \%$ majority-rule consensus tree with nodal support summarized as posterior probabilities and branch lengths averaged over all post-burn-in trees.

For the ML analyses the dataset was divided into five partitions based on DNA region identity. One thousand inferences were run from distinct random stepwise addition sequence MP starting trees under the general time reversible nucleotide substitution model (GTR; Tavaré, 1986) with among-site rate variation modelled with a gamma distribution. Subsequently, 1000 non-parametric bootstraps were performed under the partition data mode.
In the MP searches all characters were treated as unordered, independent, and of equal weight. Gaps were treated as missing data. A two-stage heuristic search strategy was applied. In the first stage, heuristic tree searches were performed using the following specifications: 1000 replicates with random taxon sequence addition, tree bisection-reconnection branchswapping (TBR), keeping multiple shortest trees found during branch-swapping (MulTrees $=$ on), saving no more than 10 trees per replicate, and all other search settings at default values. The shortest trees found in the first stage were used as starting trees in the second heuristic search using the same specifications as in the first stage, except for swapping on all optimal starting trees in the branch-swapping process (steepest=yes), and a maximum of 10,000 trees saved. Clade support was estimated with non-parametric bootstrapping with 10,000 replicates with simple sequence addition, TBR, maximally 10 trees saved per replicate, and all other settings at default values.

Ancestral character state reconstruction - Ancestral morphological character states were reconstructed for two flower and two fruit characters: (i) occurrence of an inner petal whorl: $0=$ absent; 1 = present; (ii) outer petal shape and length/ width ratio: $0=$ ovate, elliptic or triangular (length/width ratio $<6$ ); 1 = narrowly ovate, narrowly elliptic or narrowly triangular (length/width ratio $\geq 6$ ); (iii) monocarp shape: $0=$ moniliform; 1 = not moniliform; (iv) maximum seed number per monocarp: $0=1 ; 1=2 ; 2=>2$. Morphology was assessed using living material and herbarium material deposited in BKF, CANT, HITBC, HKU, K, KUN, L, NY, P, PE, UC, and WAG.

Ancestral character states were reconstructed using likelihood and parsimony methods implemented in Mesquite v.2.7.5 (Maddison \& Maddison, 2011). For the likelihood reconstruction the Mk1 model (Markov k-state 1 parameter model; Lewis, 2001) was selected. Under this model any particular change is equally probable, and the rate of change is the only parameter. In the parsimony reconstructions character-state changes were modelled as unordered. To account for phylogenetic uncertainty the "Trace over trees" option was used, and the post-burn-in trees from the MrBayes analyses were selected as input trees. The 10 outgroup taxa were pruned from the $50 \%$ majority-rule consensus tree from the Bayesian analyses prior to mapping the reconstructions onto the tree. The results of the likelihood reconstructions were summarized using the "Average Frequencies across Trees" option estimating for each node the average likelihood of each state across all trees possessing that node. The results of the parsimony reconstructions were summarized using the "Count Trees with Uniquely Best States" option estimating for each node the number of times a single character is reconstructed as most parsimonious. Reconstructions are counted as equivocal when two or more states are reconstructed as equally parsimonious at a particular node.

\section{a RESULTS}

The concatenated alignment of the 52-taxon dataset consisted of 5489 aligned positions. Descriptive statistics for the concatenated dataset and its five nucleotide partitions, 
including the number of aligned positions, the number and percentage of excluded sites, the percentage of missing data, the number and percentage of variable sites, and the number and percentage of potentially parsimony-informative sites, are given in Table 2.

Nucleotide substitution model selection using the AIC indicated the GTR nucleotide substitution model with among-site rate variation modelled with a gamma distribution $(\mathrm{GTR}+\Gamma)$ as the best-fitting model for the matK and psbA-trnH partitions. GTR $+\Gamma$ combined with a proportion of invariable sites $(\mathrm{GTR}+\Gamma+\mathrm{I})$ was selected for the $n d h F, r b c L$, and $t r n L-F$ partitions, the non-coding data partition, the coding data partition, as well as for the concatenated data matrix.

Partitioning considerably improved mean $-\ln L$ values in the Bayesian analyses (mean $-\ln L_{\text {unpartitioned }}=17,679$; mean $-\ln L_{2 \text { partitions }}=17,664$; mean $-\ln L_{\text {spartitions }}=17,492$ ). Bayes factor comparison indicated that the analyses using five partitions based on region identity provided distinctly better explanations of the data than both analyses using two partitions based on coding and non-coding DNA region identity and analyses of the unpartitioned dataset. The subsequent presentation of the results of the Bayesian analyses is therefore limited to the trees derived from the analyses using five partitions.

The $50 \%$ majority-rule consensus tree resulting from the Bayesian analyses is shown in Fig. 2. Two main clades can be distinguished within the strongly supported desmoid clade (posterior clade probability, PP: 1; ML bootstrap percentage, $\mathrm{BP}_{\mathrm{ML}}$ : 100; MP bootstrap percentage, $\mathrm{BP}_{\mathrm{MP}}$ : 100): Clade $\mathrm{A}$ (PP: 1; $\mathrm{BP}_{\mathrm{ML}}$ : 98; $\mathrm{BP}_{\mathrm{MP}}$ : 98) comprises a grade of three African species of Friesodielsia and a clade consisting of species belonging to the African genus Monanthotaxis. Clade A is sister to clade $\mathrm{B}$ (PP: 1; $\mathrm{BP}_{\mathrm{ML}}: 83$; $\mathrm{BP}_{\mathrm{MP}}: 80$ ), which consists of all sampled species of Dasymaschalon and Desmos, as well as Asian species of Friesodielsia.

Within clade B, three moderately to strongly supported subclades can be differentiated (clades B1, B2 and B3), although relationships among these subclades are not resolved or only poorly supported. Clade $\mathrm{B} 1$ is well supported (PP: $1 ; \mathrm{BP}_{\mathrm{ML}}$ : 98 ; $\mathrm{BP}_{\mathrm{MP}}$ : 93). It comprises a poorly supported clade of three Asian Friesodielsia species and a moderately to well supported clade of three Dasymaschalon species (D. filipes, D. longiflorum (Roxb.) Finet \& Gagnep., D. tibetense X.L. Hou). Clade B2 (PP: $\left.1 ; \mathrm{BP}_{\mathrm{ML}}: 89 ; \mathrm{BP}_{\mathrm{MP}}: 84\right)$ includes all eight species of Desmos sampled. Clade $\mathrm{B} 3$ (PP: 1; $\mathrm{BP}_{\mathrm{ML}}$ : 98; $\mathrm{BP}_{\mathrm{MP}}$ : 98) consists of all Dasymaschalon species sampled other than those retrieved in clade B1. The backbone of clade B3 is only poorly resolved and poorly supported, but four moderately to well supported subclades can be differentiated.

The results indicate that Friesodielsia is polyphyletic. African Friesodielsia species are retrieved in clade A and are closely related to Monanthotaxis, whilst Asian Friesodielsia species fall in clade B1. Dasymaschalon is not monophyletic as three species in clade B1 show a closer relationship to Asian Friesodielsia species than to the major Dasymaschalon clade (B3). Desmos and Monanthotaxis are supported as monophyletic.

The results of the ancestral character reconstructions are presented in Figs. 3-4.

\section{DISCUSSION}

Intergeneric relationships in the desmoid clade. - The present study represents the first molecular phylogenetic analysis of the desmoid clade to be based on a moderately dense species sampling (ca. $25 \%$ of the species diversity of the constituent genera) including samples of the type species of the four constituent genera. While Desmos and Monanthotaxis are supported as monophyletic, the analyses reveal problems in the delimitation of Dasymaschalon and Friesodielsia.

The inferred sister relationship between the African clade A, including Monanthotaxis and some Friesodielsia species, and the Asian clade B consisting of Desmos, Dasymaschalon and some Friesodielsia species is consistent with the results of the molecular phylogenetic analyses of Couvreur \& al. (2011) and palynological data. The pollen exine of Desmos, Dasymaschalon and Asian Friesodielsia species is predominantly echinate, whereas that of Monanthotaxis and African Friesodielsia species is verrucate to microbaculate (Walker, 1971).

Number of petals per whorl can show a certain degree of plasticity in some Annonaceae species, e.g., some collections of $D$. longiflorum have only two petals per flower (Wang $\&$ al., 2009), and changes of petal number within a whorl occur frequently in Annonaceae and are generally of minor phylogenetic significance (Saunders, 2010). In contrast to this, singlewhorled corollas are relatively rare in Annonaceae and have, apart from Dasymaschalon, evolved in only three other disparate lineages: within Anaxagorea A. St.-Hil. (subfam. Anaxagoreoideae), Annickia Setten \& Maas (subfam. Malmeoideae), and Annona L. (subfam. Annonoideae) (Saunders, 2010). Given the rarity of single-whorled, three-petalled corollas in Annonaceae, and the distinct flower morphology of Dasymaschalon characterised by a pollination chamber formed by outer petal homologues, the inferred non-monophyly of the genus is unexpected. The majority of Dasymaschalon species fall into one well supported clade (B3), which also includes the type species of the genus, D. dasymaschalum. Dasymaschalon could be rendered monophyletic, therefore, by removal of the strongly supported clade consisting of the three species (D. filipes, D. longiflorum, D. tibetense) which fall in a strongly supported clade with Asian Friesodielsia species (clade B1). The Dasymaschalon species in clade B1 are characterized by conspicuously long, narrow petals (Fig. 1C). Petal size is variable in Dasymaschalon: D. evrardii has the smallest flowers, with petals less than $1 \mathrm{~cm}$ long, whilst four taxa have petals longer than $10 \mathrm{~cm}$ (D. grandiflorum: ca. $17 \mathrm{~cm} ;$ D. megalanthum (Merr.) Merr.: $3.0-10.5 \mathrm{~cm}$; D. filipes: $3.0-15.5 \mathrm{~cm}$; and D. longiflorum: $5.0-16.5 \mathrm{~cm}$ ). Petal width does not show such great variation, ranging from 5 to $35 \mathrm{~mm}$; the resultant petal length/width ratios are in the range 1.5-6.0 for all species in clade B3, but 6-17 for those in clade B1 (Figs. 1C, 3B). Dasymaschalon filipes, $D$. longiflorum and $D$. tibetense also show maximally two-seeded monocarps, which distinguishes them from most species in the genus. They share this character with closely related Asian Friesodielsia species. However, the seed number per monocarp is a highly variable character within the desmoid clade and single-seeded or maximally two-seeded 

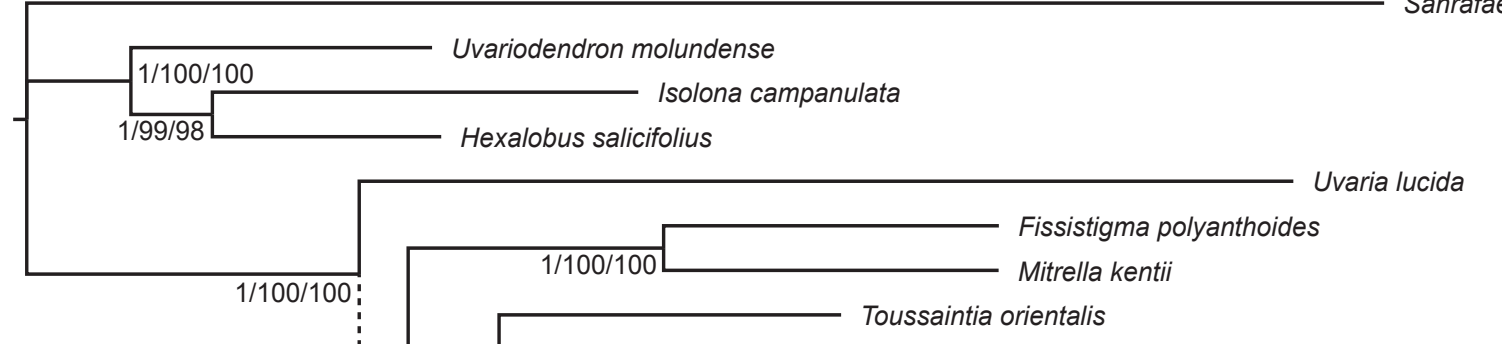

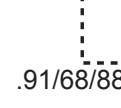

$91 / 68 / 8$
Fig. 2. Bayesian 50\% majority-rule consensus tree (cpDNA data: matK, $n d h F, p s b A-t r n H, r b c L, t r n L-F ; 52$ taxa). Bayesian posterior probability (PP) support values $>0.9$ and bootstrap support values $>50$ of the maximum likelihood $\left(\mathrm{BP}_{\mathrm{ML}}\right)$ and maximum parsimony $\left(\mathrm{BP}_{\mathrm{MP}}\right)$ analyses are indicated at each node: $\mathrm{PP} / \mathrm{BP}_{\mathrm{ML}} / \mathrm{BP}_{\mathrm{MP}}$. Broken lines indicate branches which lead to nodes with a $\mathrm{PP}<0.95$ and/or $\mathrm{BP}<70$.

Toussaintia orientalis

Sphaerocoryne sp.

1/100/100 Sphaerocoryne gracilis

Friesodielsia sp.

1/100/100 L Friesodielsia enghiana

Friesodielsia obovata

Monanthotaxis glomerulata

$\sqrt{0.90 / *}$ Monanthotaxis whytei

:- $0.93 / 54 / 51$

Monanthotaxis congoensis

\begin{tabular}{l|l}
$1 / 71 / 71$ & Monanthotaxis schweinfurthii \\
\hline & Monanthotaxis buchananii
\end{tabular}

$0.94 / * \leftarrow \times \leftarrow$ Monanthotaxis fornicata

1/100/100 L Monanthotaxis trichocarpa

${ }^{* / 58 /{ }^{*}}$ Friesodielsia desmoides
$1 / 100 / 100$
$1 / 98 / 93$ Friesodielsia biglandulosa

$1 / 100 / 100$

$1 / 1 / 100 / 100 \_$Friesodielsia cuneiformis

Dasymaschalon filipes

1/85/87— Dasymaschalon longiflorum

$1 / 99 / 97$ Desmos elegans
Desmos wardianus
0.98/87/65 Desmos Deanus

1/99/98 Dasymaschalon acuminatum

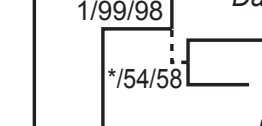

- Dasymaschalon rostratum

Dasymaschalon longiusculum

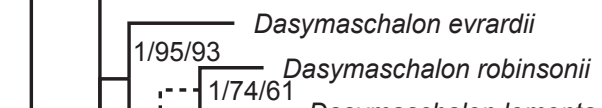

1/98/98 Dasymaschalon lomentaceum

1/98/99 D Dasymaschalon dasymaschalum

1/99/99 Dasymaschalon sootepense

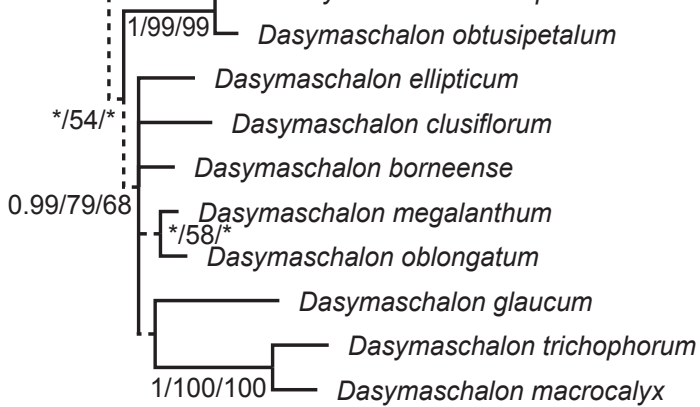



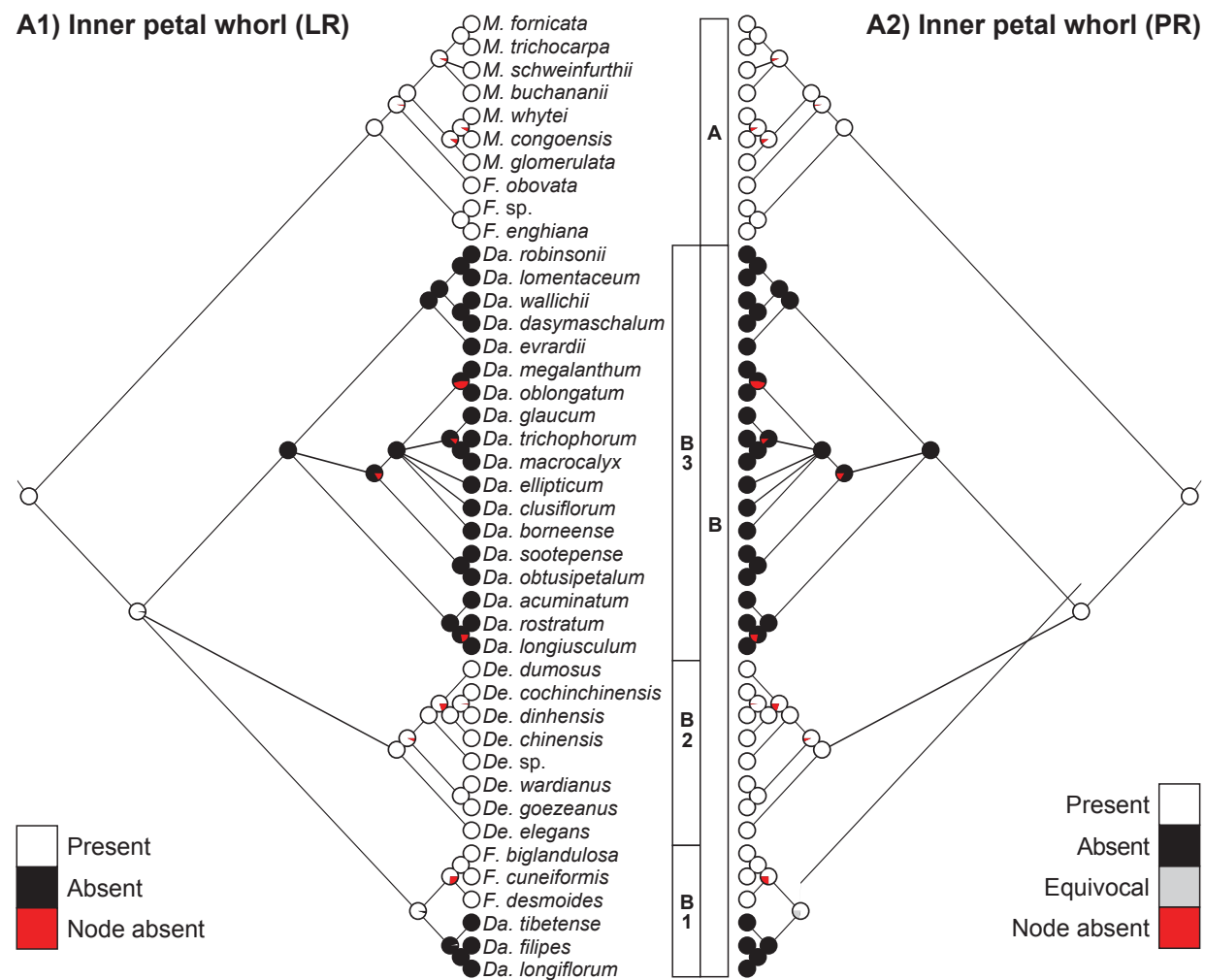

B1) Petal length/width ratio (LR) $\mathrm{QM}$. fornicata OM. trichocarpa OM. schweinfurthii OM. buchananii M. whytei
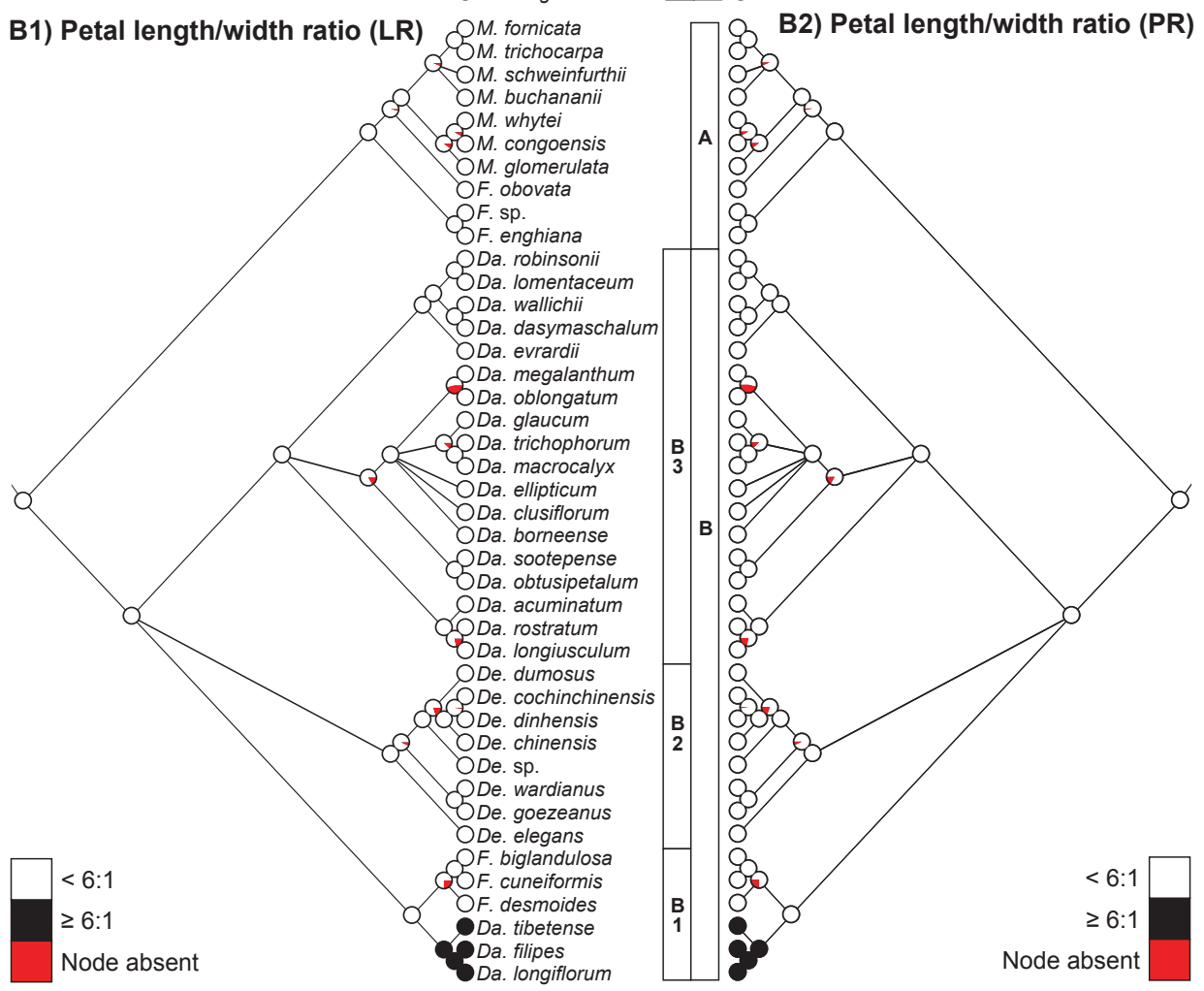

Fig. 3. Ancestral character reconstructions for the desmoid clade: A, inner petal whorl presence/absence and B, petal length/width ratio. Likelihood reconstructions (LR) are shown on the left (A1, B1); parsimony reconstructions (PR) on the right (A2, B2). Character reconstructions across 30,000 Bayesian input trees are summarised and mapped on the Bayesian majority-rule consensus tree (cpDNA data: $m a t K, n d h F, p s b A$-trnH, $r b c L, \operatorname{trnL}-F ; 52$ taxa). Pie charts in the likelihood reconstructions at each node show the percentage of node absence in the input trees and the average likelihood received by each state across all input trees possessing that node. Pie charts in the parsimony reconstructions show the percentage of node absence, and the percentage of reconstructions of a single most parsimonious character at each node (reconstructions are counted as equivocal when two or more states are reconstructed as equally parsimonious). 

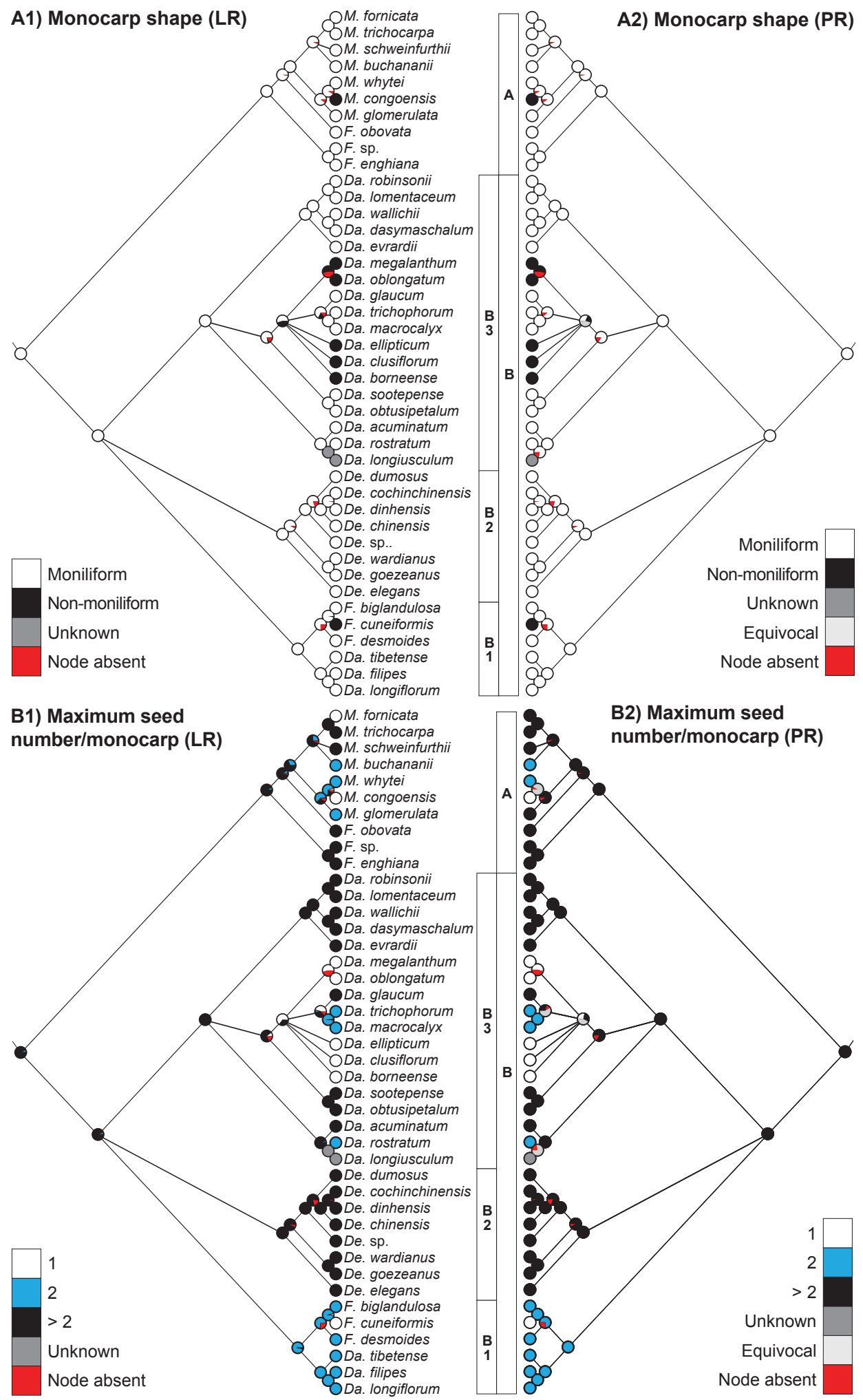

Fig. 4. Ancestral character reconstructions for the desmoid clade: $\mathbf{A}$, monocarp shape and $\mathbf{B}$, maximum seed number per monocarp. Likelihood reconstructions (LR) are shown on the left (A1, B1); parsimony reconstructions (PR) on the right (A2, B2). Character reconstructions across 30,000 Bayesian input trees are summarised and mapped on the Bayesian majority-rule consensus tree (cpDNA data: $m a t K, n d h F, p s b A-t r n H, r b c L$, $\operatorname{trnL}-F ; 52$ taxa). Pie charts in the likelihood reconstructions at each node show the percentage of node absence in the input trees and the average likelihood received by each state across all input trees possessing that node. Pie charts in the parsimony reconstructions show the percentage of node absence, and the percentage of reconstructions of a single most parsimonious character at each node (reconstructions are counted as equivocal when two or more states are reconstructed as equally parsimonious). 
monocarps occur in several other groups, including subclades of the major Dasymaschalon clade (Fig. 4B).

The congeneric status of African and Asian Friesodielsia species has been questioned in palynological (Walker, 1971), macromorphological (Verdcourt, 1971; Heusden, 1992) and molecular phylogenetic studies (Bygrave, 2000; Richardson \& al., 2004; Couvreur \& al., 2011). Palynological data (Walker, 1971) indicated that African Friesodielsia species with coarsely verrucate pollen exines are not congeneric with Asian Friesodielsia species, which have echinate pollen. Verdcourt (1971) used macromorphological data to differentiate the monotypic African subgenus Amblymitra Verdc. (Friesodielsia obovata (Benth.) Verdc.), the small African subgenus Oxymitropsis Verdc. (Friesodielsia enghiana (Diels) Verdc. ex Le Thomas, F. hirsuta (Benth.) Steenis, F. velutina (Sprague \& Hutch.) Steenis) and the large African-Asian subgenus Friesodielsia (the remaining species) in Friesodielsia. He stressed that Asian and African species in F. subg. Friesodielsia may not be congeneric, outlining the morphological differences: Asian Friesodielsia species have elongate flowers with outer petals that are much longer than the inner, and monocarps with one or two seeds, whilst African Friesodielsia species have wider flowers with less marked difference in shape and size between the inner and outer petals, and monocarps with one to five seeds. Verdcourt (1971) also noted that morphological differences between the small African subgenera (subg. Amblymitra, subg. Oxymitropsis) and subg. Friesodielsia may warrant separation of the former as distinct genera, although he refrained from formalizing this. The hypotheses of a distant relationship between the African and Asian species of the genus were later supported by molecular phylogenetic analyses by Richardson $\&$ al. (2004), Couvreur \& al. (2011) and Chatrou \& al. (2012), which included six, five and eight species of genera of the desmoid clade, respectively. The phylogenetic analyses of $r b c L$ and $\operatorname{trnL}-F$ sequence data presented in the unpublished dissertation by Bygrave (2000) included a slightly denser taxon sampling (14 species from the desmoid clade), but while the desmoid clade was strongly supported, most internal relationships received only poor bootstrap support. In Bygrave's analyses, the African species Friesodielsia gracilipes (Benth.) Steenis (F. subg. Friesodielsia), however, was shown to be closely related to Cleistochlamys Oliv., Sphaerocoryne (Boerl.) Scheff. ex Ridl., and Toussaintia Boutique rather than the desmoid clade (Bygrave, 2000). The analyses presented here corroborate previous hypotheses of the polyphyletic status of Friesodielsia and provide some new insights into the relationships of the genus. African species in F. subg. Amblymitra and subg. Oxymitropsis fall into a strongly supported clade with Monanthotaxis, and are only distantly related to Asian representatives of Friesodielsia subg. Friesodielsia, including the type species of the genus, F. cuneiformis. Asian Friesodielsia species fall into a well supported clade with three species of the Asian genus Dasymaschalon (D. filipes, D. longiflorum, D. tibetense).

Morphological character evolution in Dasymaschalon. - The basic floral architecture in Annonaceae includes two whorls of three petals, although changes in petal number (arising from the gain or loss of either single petals or entire whorls of petals) have been extensively reported (reviewed by Saunders, 2010). Dasymaschalon flowers have only three petals (Fig. 1A-C), which are interpreted to be homologous with the outer petals of other Annonaceae species based on their position relative to the outer perianth whorl (Fig. 5A). The character reconstructions presented here indicate that the loss of inner petals occurred independently in the two Dasymaschalon lineages (clades B1 and B3 in Fig. 3A).

Dasymaschalon flowers are not only unusual in lacking the inner whorl of petals, but also in the structure and function of the remaining petals. Although the three petals are homologous with the outer petals of other Annonaceae, they are structurally similar to the inner petals of many other Annonaceae species, including the closely related Friesodielsia species (Fig. 1F): they are apically connivent, forming a partially enclosed pollination chamber, and have correspondingly broad margins that allow adhesion between contiguous petals. Pollination chambers, although not ubiquitous, are a crucial feature of the pollination biology of most Annonaceae species. The suite of morphological changes in the "outer" petals so that they resemble the pollination chamber-forming inner petals may indicate strong selective advantages of a corolla partially enclosing the mature reproductive organs. This provides a potential functional explanation for the evolution of pollination chambers in the two Dasymaschalon lineages subsequent to the loss of the inner petals. Alternatively, however, the loss of the inner petals and the correlated morphological changes of the outer petals may be non-adaptive and explained by a disruption to the homeotic control of floral organ identity in accordance with the "ABC" model of floral genetic control (Bowman \& al., 1991; Coen \& Meyerowitz, 1991). This model has recently been shown to be applicable, albeit in a slightly modified form, to early-divergent angiosperms, including Annonaceae (Kim \& al., 2005). It can be hypothesized that the genetic control of floral organ development in ancestors of the two Dasymaschalon lineages may have been disrupted, with a homeotic shift of inner petal to stamen identity, and an associated shift in the remaining petals from outer petal to inner petal identity (Saunders, 2010).

The androecia of most Annonaceae flowers possess an outermost whorl of six stamens in three pairs (Ronse de Craene \& Smets, 1990; Leins \& Erbar, 1996; Xu \& Ronse de Craene, 2010), with the pairing either due to the transition between helical and whorled organ arrangements or due to stamen doubling associated with differing sizes of petals and stamens (discussed by Xu \& Ronse de Craene, 2010). Dasymaschalon flowers possess an outermost whorl of four stamens alternately arranged relative to the petals, with one pair and two solitary stamens at the corners of a triangular floral meristem (Fig. 5). This may indicate the gain of an outer whorl of stamens consistent with the hypothesis of a homeotic shift in organ identity from inner petals to stamens. Centripetal and centrifugal homeotic shifts of organ identity have been hypothesised to explain the flower morphology of several other Annonaceae species (Saunders, 2010). Studies determining homeotic gene expression patterns in these species are required to further investigate these hypotheses. 
A third possible explanation for the observed pattern of apparently parallel evolution of the complex corolla syndrome in the two Dasymaschalon clades is reticulation, chloroplast capture and subsequent diversification. The phylogenetic analyses in the current study, as in previous studies on the phylogenetics of Annonaceae, are solely based on cpDNA, so that reticulation and chloroplast capture cannot be ruled out. This highlights the need for the development of nuclear markers which work reliably across Annonaceae.

The gynoecia of species in the desmoid clade are apocarpous and the monocarps are usually distinctly stipitate. Variation in monocarp shape in the desmoid clade is influenced by the number of seeds per monocarp. In general, single-seeded monocarps are globose or ellipsoid, whereas multi-seeded monocarps typically show distinct constrictions between neighbouring seeds (Fig. 4A, B). In some species single-seeded and moniliform monocarps occur/are present in the same fruit (Fig. 1I, L), but this reflects incomplete fertilization of ovules rather than differences in ovule number.

The constrictions between seeds, and sequential ripening of the single-seeded units in moniliform monocarps (e.g., Fig. 1J), enable sequential removal of the single-seeded units from the monocarp by birds, the primary frugivores, promoting effective dispersal. Evolutionary changes in seed size are likely to be constrained by the beak gape of frugivorous birds. Dasymaschalon sootepense Craib has the largest seeds in Dasymaschalon (17.5$24.0 \mathrm{~mm}$ long and $4-5 \mathrm{~mm}$ in diameter); although these seeds are relatively long, their width remains within the maximum beak gape of common bird frugivores, thereby enabling the seeds to be swallowed whole and subsequently regurgitated.
Multiple transitions from multi-seeded monocarps to maximally two-seeded or single-seeded monocarps are inferred in the desmoid clade (Fig. 4B). The Asian Friesodielsia species have single-seeded or maximally two-seeded monocarps (e.g., F. kingii, Fig. 1K) distinguishing them from most African representatives of the genus (Verdcourt, 1971). There is considerable diversity of monocarp morphology and seed number within all genera of the desmoid clade, however, and while seed numbers are of considerable diagnostic value at species level, they have limited utility in generic circumscriptions.

\section{CONCLUSIONS}

The genus Dasymaschalon has traditionally been circumscribed with the clear diagnostic characteristic of a single petal whorl and the formation of a pollination chamber by petals that are homologous to the outer petals of other Annonaceae genera. The inferred non-monophyly of the genus is surprising as the two inferred Dasymaschalon lineages share a complex corolla syndrome. The evolution of this syndrome not only involves the loss of the inner petal whorl, but a suite of associated morphological changes are required for the formation of an "outer" petal pollination chamber that mirrors the inner petal pollination chambers of other Annonaceae. This phenomenon may be explained by the strong selective advantages of a corolla partially enclosing the mature stamens and carpels, or as the consequence of disruptions to homeotic gene expression with the loss of inner petals (possibly resulting from a shift in organ identity from inner petals to stamens, and therefore associated
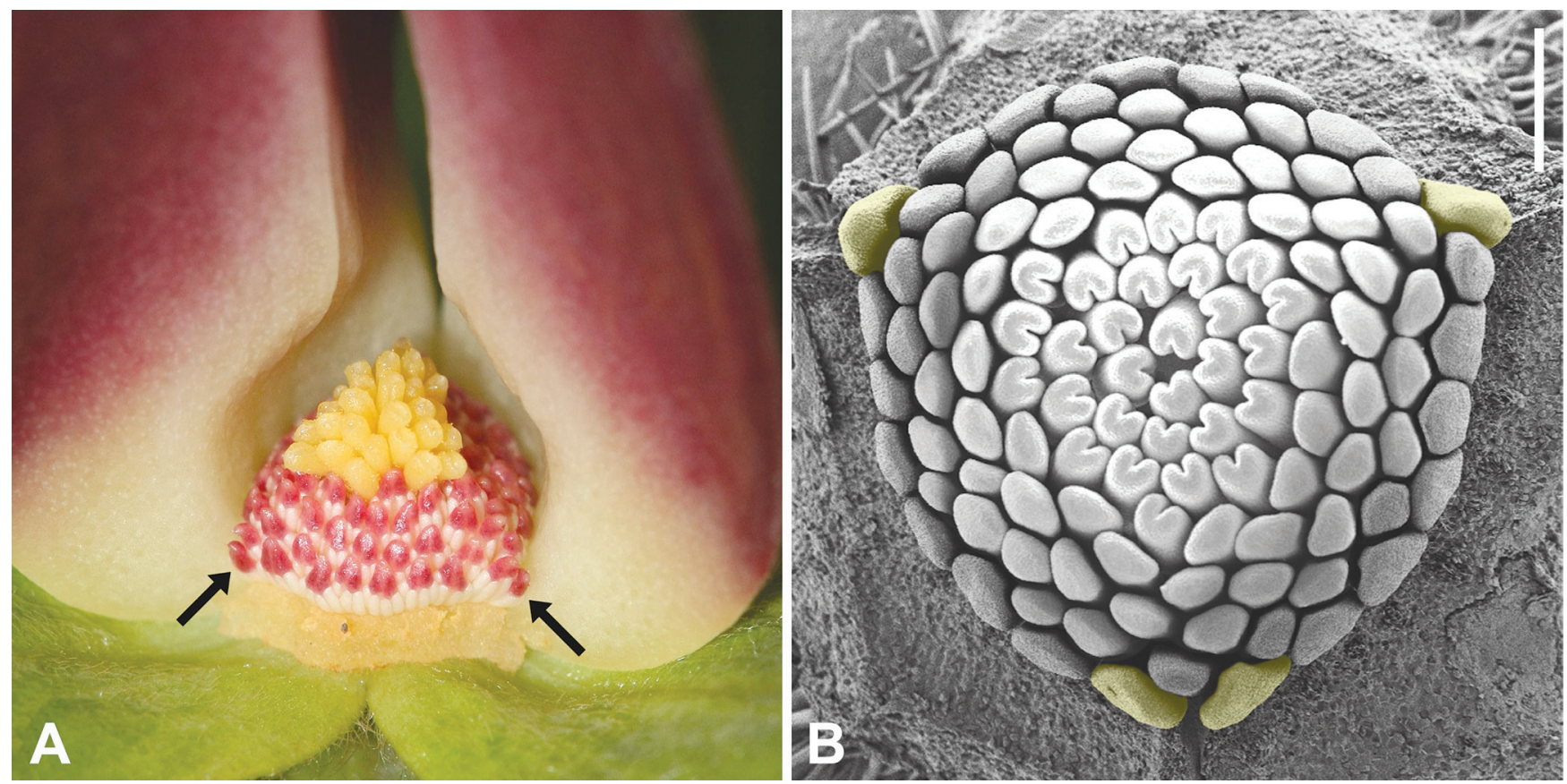

Fig. 5. Stamen arrangement in Dasymaschalon trichophorum. A, Mature flower with proximal petal removed, exposing stamens and carpels; two of the outermost stamens indicated by arrows; B, flower bud after removal of perianth (scanning electron micrograph); outermost stamens indicated in colour (scale bar: $0.25 \mathrm{~mm}$ ). - A, B, Pang Chun Chiu s.n. (HKU). Photographs: A, Pang Chun Chiu; B, Zhou Wanqing. 
with the gain of an additional whorl of stamens), and the homeotic shift in the remaining petals from outer petal to inner petal identity.

The results of the present study, with enhanced sampling of taxa and DNA regions, corroborate previous hypotheses of the polyphyly of Friesodielsia. More extensive taxon sampling and morphological work will be necessary, however, to clarify (1) whether the African Friesodielsia species should be transferred to Monanthotaxis, or the African Friesodielsia-Monanthotaxis clade should be segregated into two or more genera; and (2) whether the three orphan Dasymaschalon species (D. filipes, D. longiflorum, D. tibetense) should be separated as a distinct genus or merged with Friesodielsia. A phylogenetic framework based on a robust taxon-sample of Friesodielsia will be essential as a basis for the re-circumscription of genera in the desmoid clade. In addition, data from nuclear markers is required to investigate whether hybridisation and chloroplast capture have occurred in the evolutionary history of the desmoid clade.

\section{ACKNOWLEDGEMENTS}

The research was supported by grants from the Hong Kong Research Grants Council (HKU 7578/05M), awarded to RMKS and YCFS, and a University of Hong Kong Research Committee grant, awarded to RMKS. We are grateful to the curators of CANT, HITBC, KUN, L, NY, P and WAG herbaria and Bogor Botanic Garden for providing leaf material; Piya Chalermglin, Pang Chun Chiu, Wang Ruijiang, Garry Sankowsky, Wisnu H. Ardi and Mark Hughes for field collections; Sid Surveswaran for sequencing Dasymaschalon acuminatum; Piya Chalermglin, Pang Chun Chiu, Thomas Couvreur and Zhou Wanqing for the use of their photographs; Tang Chin Cheung for primer design; Laura Wong for technical assistance; and Jim Doyle, Thomas Couvreur and Michael Pirie for their constructive comments on earlier versions of the manuscript.

\section{LITERATURE CITED}

Bowman, J.L., Smyth, D.R. \& Meyerowitz, E.M. 1991. Genetic interactions among floral homeotic genes of Arabidopsis. Development 112: 1-20.

Brown, J.M., Hedtke, S.M., Lemmon, A.R. \& Lemmon, E.M. 2010 When trees grow too long: Investigating the causes of highly inaccurate Bayesian branch length estimates. Syst. Biol. 59: $145-161$.

Bygrave, P.C. 2000. Molecular systematics of the Annonaceae Juss. Ph.D. thesis, University of Reading, Reading, U.K.

Chalermglin, P. 2001. Family Annonaceae. Bangkok: Ban \& Suan.

Chatrou, L.W., Pirie, M.D., Erkens, R.H.J., Couvreur, T.L.P., Neubig, K.M., Abbott, J.R., Mols, J.B., Maas, J.W., Saunders, R.M.K. \& Chase, M.W. 2012. A new subfamilial and tribal classification of the pantropical flowering plant family Annonaceae informed by molecular phylogenetics. Bot. J. Linn. Soc. 169: 5-40.

Coen, E.S. \& Meyerowitz, E.M. 1991. The war of the whorls: Genetic interactions controlling flower development. Nature 353: 31-37.

Couvreur, T.L.P., Pirie, M.D., Chatrou, L.W., Saunders, R.M.K., Su, Y.C.F., Richardson, J.E. \& Erkens, R.H.J. 2011. Early evolutionary history of the flowering plant family Annonaceae: Steady diversification and boreotropical geodispersal. J. Biogeogr. 38: 664-680.

Doyle, J. \& Doyle, J.L. 1987. A rapid DNA isolation method for small quantities of fresh tissues. Phytochem. Bull. 19: 11-15.

Doyle, J.A. \& Le Thomas, A. 2012. Evolution and phylogenetic significance of pollen in Annonaceae. Bot. J. Linn. Soc. 169: 190-221.

Drummond, A.J., Ashton, B., Buxton, S., Cheung, M., Cooper, A., Heled, J., Kearse, M., Moir, R., Stones-Havas, S., Sturrock, S., Thierer, T. \& Wilson, A. 2010. Geneious, version 5.1. http://www geneious.com/.

Erkens, R.H.J. 2007. From morphological nightmare to molecular conundrum. Phylogenetic, evolutionary and taxonomic studies on Guatteria (Annonaceae). Ph.D. thesis, Utrecht University, Utrecht, The Netherlands.

Erkens, R.H.J., Cross, H., Maas, J.W., Hoenselaar, K. \& Chatrou, L.W. 2008. Age and greenness of herbarium specimens as predictor for successful extraction and amplification of DNA. Blumea 53: $407-428$.

Heusden, E.C.H. van. 1992. Flowers of Annonaceae: Morphology, classification, and evolution. Blumea Suppl. 7: 1-218.

Huelsenbeck, J.P. \& Ronquist, F. 2001. MrBayes: Bayesian inference of phylogenetic trees. Bioinformatics 17: 754-755.

Kass, R.E. \& Raftery, A.E. 1995. Bayes factors. J. Amer. Statist. Assoc. 90: 773-795.

Katoh, K., Asimenos, G. \& Toh, H. 2009. Multiple alignment of DNA sequences with MAFFT. Meth. Molec. Biol. 537: 39-64.

Kim, S., Koh, J., Yoo, M.J., Kong, H.Z., Hu, Y., Ma, H., Soltis, P.S. \& Soltis, D.E. 2005. Expression of floral MADS-box genes in basal angiosperms: Implications for the evolution of floral regulators. Plant J. 43: 724-744.

Le Thomas, A. 1980. Ultrastructural characters of the pollen grains of African Annonaceae and their significance for the phylogeny of primitive angiosperms: First part. Pollen \& Spores 22: 267-342.

Le Thomas, A. 1981. Ultrastructural characters of the pollen grains of African Annonaceae and their significance for the phylogeny of primitive angiosperms: Second part. Pollen \& Spores 23: 5-36.

Leins, P. \& Erbar, C. 1996. Early floral development studies in Annonaceae. Pp. 1-27 in: Morawetz, W. \& Winkler, H. (eds.), Reproductive morphology in Annonaceae. Vienna: Österreichische Akademie der Wissenschaften.

Lewis, P.O. 2001. A likelihood approach to estimating phylogeny from discrete morphological character data. Syst. Biol. 50: 913-925.

Li, P.T. 1993. Novelties in Annonaceae from Asia. Guihaia 13: 311-315.

Maddison, W.P. \& Maddison, D.R. 2011. Mesquite: A modular system for evolutionary analysis, version 2.7.5. http://mesquiteproject.org/ mesquite/mesquite.html.

Marshall, D.C. 2010. Cryptic failure of partitioned Bayesian phylogenetic analyses: Lost in the land of long trees. Syst. Biol. 59: $108-117$.

Maxwell, J.F. 1989. Botanical notes on the vascular flora of Chiang Mai Province, Thailand. Nat. Hist. Bull. Siam Soc. 37: 177-185.

Miller, M.A., Pfeiffer, W. \& Schwartz, T. 2010. Creating the CIPRES Science Gateway for inference of large phylogenetic trees. Pp. 1-8 in: Proceedings of the Gateway Computing Environments Workshop (GCE). New Orleans: IEEE.

Newton, M.A. \& Raftery, A.E. 1994. Approximate Bayesian inference with the weighted likelihood bootstrap. J. Roy. Statist. Soc., Ser. B 56: 3-48.

Nylander, J.A.A. 2004. MrModeltest, version 2.3. http://www.abc .se/ nylander.

Nylander, J.A.A., Wilgenbusch, J.C., Warren, D.L. \& Swofford, D.L. 2008. AWTY (Are we there yet?): A system for graphical exploration of MCMC convergence in Bayesian phylogenetics. Bioinformatics 24: 581-583.

Olmstead, R.G. \& Sweere, J.A. 1994. Combining data in phylogenetic systematics: An empirical approach using three molecular data sets in the Solanaceae. Syst. Biol. 43: 467-481. 
Pirie, M.D., Chatrou, L.W., Mols, J.B., Erkens, R.H.J. \& Oosterhof, J. 2006. 'Andean-centred' genera in the short-branch clade of Annonaceae: Testing biogeographical hypotheses using phylogeny reconstruction and molecular dating. J. Biogeogr. 33: 31-46.

Rainer, H. \& Chatrou, L.W. 2006. Global taxonomic/nomenclatural index for the plant family Annonaceae Juss. http://herbarium. botanik.univie.ac.at/annonaceae/listTax.php.

Rambaut, A. \& Drummond, A.J. 2009. Tracer, version 1.5. http:// beast.bio.ed.ac.uk/Tracer.

Richardson, J.E., Chatrou, L.W., Mols, J.B., Erkens, R.H.J. \& Pirie, M.D. 2004. Historical biogeography of two cosmopolitan families of flowering plants: Annonaceae and Rhamnaceae. Philos. Trans., Ser. B 359: 1495-1508.

Ronquist, F. \& Huelsenbeck, J.P. 2003. MrBayes 3: Bayesian phylogenetic inference under mixed models. Bioinformatics 19: 1572-1574.

Ronse de Craene, L. \& Smets, E. 1990. The floral development of Popowia whitei (Annonaceae). Nord. J. Bot. 10: 411-420.

Saunders, R.M.K. 2010. Floral evolution in the Annonaceae: Hypotheses of homeotic mutations and functional convergence. Biol. Rev. Cambridge Philos. Soc. 85: 571-591.

Saunders, R.M.K. 2012. The diversity and evolution of pollination systems in Annonaceae. Bot. J. Linn. Soc. 169: 222-244.

Sinclair, J. 1955. A revision of the Malayan Annonaceae. Gard. Bull. Singapore 14: 149-516.

Stamatakis, A. 2006. RAxML-VI-HPC: Maximum likelihood-based phylogenetic analyses with thousands of taxa and mixed models. Bioinformatics 22: 2688-2690.

Su, Y.C.F., Smith, G.J.D. \& Saunders, R.M.K. 2008. Phylogeny of the basal angiosperm genus Pseuduvaria (Annonaceae) inferred from five chloroplast DNA regions, with interpretation of morphological character evolution. Molec. Phylogenet. Evol. 48: 188-206.

Suchard, M.A., Weiss, R.E. \& Sinsheimer, J.S. 2001. Bayesian selection of continuous-time Markov chain evolutionary models. Molec. Biol. Evol. 18: 1001-1013.

Swofford, D.L. 2002. PAUP*: Phylogenetic analysis using parsimony (*and other methods), version 4.0b10, Sunderland, Massachusetts: Sinauer.

Tavaré, S. 1986. Some probabilistic and statistical problems in the analysis of DNA sequences. Pp. 57-86 in: Miura, R.D. (ed.), Some mathematical questions in biology: DNA sequence analysis. Providence, Rhode Island: American Mathematical Society.

Verdcourt, B. 1971. Notes on East African Annonaceae. Kew Bull. 25: $1-34$.

Walker, J.W. 1971. Pollen morphology, phytogeography, and phylogeny of the Annonaceae. Contr. Gray Herb. 202: 1-131.

Wang, J., Chalermglin, P. \& Saunders, R.M.K. 2009. The genus Dasymaschalon (Annonaceae) in Thailand. Syst. Bot. 34: 252-265.

Xu, F. \& Ronse de Craene, L. 2010. Floral ontogeny of Annonaceae: Evidence for high variability in floral form. Ann. Bot. (Oxford) 106: 591-605.

Zhou, L., Su, Y.C.F., Chalermglin, P. \& Saunders, R.M.K. 2010. Molecular phylogenetics of Uvaria (Annonaceae): Relationships with Balonga, Dasoclema and Australian species of Melodorum. Bot. J. Linn. Soc. 163: 33-43.

Zhou, L., Su, Y.C.F. \& Saunders, R.M.K. 2009. Molecular phylogenetic support for a broader delimitation of Uvaria (Annonaceae), inclusive of Anomianthus, Cyathostemma, Ellipeia, Ellipeiopsis and Rauwenhoffia. Syst. Biodivers. 7: 249-258.

\begin{abstract}
Appendix. Species names and GenBank accession numbers of DNA sequences used in this study. Voucher data is given for accessions, for which DNA sequences were newly obtained, using the following format: Taxon name, country, largest political subdivision, collector(s) and collector number, herbarium acronym: matK, $n d h F, p s b A$-trnH, $\operatorname{trnL}-F, r b c L$ GenBank accession numbers. -: missing data; *: newly generated sequences.
\end{abstract}

Dasymaschalon acuminatum Jing Wang \& R.M.K. Saunders, Thailand, cultivated in the private collection of P. Chalermglin (Bangkok), Chalermglin 490520, HKU: JQ768546*, JQ768587*, JQ768625*, JQ768666*, JQ768706*. Dasymaschalon borneense Nurmawati, Indonesia, Kalimantan Timur, Ambriansyah \& Arifin 1687, L: JQ768547*, -, JQ768626*, JQ768667*, JQ768707*. Dasymaschalon clusiflorum (Merr.) Merr., Philippines, Luzon, Ramos \& Edaño 45293, NY: JQ768548*, -, JQ768627*, JQ768668*, JQ768708*. Dasymaschalon dasymaschalum (Blume) I.M. Turner, Thailand, cultivated in the private collection of P. Chalermglin (Bangkok), Saunders 04/26, HKU: JQ768549*, JQ768588*, JQ768628*, JQ768669*, JQ768709*. Dasymaschalon ellipticum Nurmawati, Brunei, Kalat \& al. 15734, L: JQ768550*, JQ768589*, JQ768629*, JQ768670*, JQ768710*. Dasymaschalon evrardii Ast, Vietnam, Annam, Poilane 9615, P: JQ768551*, JQ768590*, JQ768630*, JQ768671*, JQ768711*. Dasymaschalon filipes (Rid1.) Bân, Thailand, Nakhon Si Thammarat, Van Beusekom \& Phengkhlai 835, L: JQ768552*, JQ768591*, JQ768631*, JQ768672*, JQ768712*. Dasymaschalon glaucum Merr. \& Chun, Thailand, Ratchaburi, Chalermglin 510521, HKU: JQ768553*, JQ768592*, JQ768632*, JQ768673*, JQ768713*. Dasymaschalon lomentaceum Finet \& Gagnep., Thailand, cultivated in the private collection of P. Chalermglin (Bangkok), Saunders 04/5, HKU: JQ768554*, JQ768593*, JQ768633*, JQ768674*, JQ768714*. Dasymaschalon longiflorum (Roxb.) Finet \& Gagnep., India, Assam, Chand 5567A, L: JQ768555*, JQ768594*, JQ768634*, JQ768675*, JQ768715*. Dasymaschalon longiusculum (Bân) Jing Wang \& R.M.K. Saunders, Vietnam, Tonkin, Van der Werff \& Nguyen 14292, L: JQ768556*, -, JQ768635*, JQ768676*, JQ768716*. Dasymaschalon macrocalyx Finet \& Gagnep., Thailand, cultivated in the private collection of P. Chalermglin (Bangkok), Saunders 04/6, HKU: JQ768557*, JQ768595*, JQ768636*, JQ768677*, JQ768717*. Dasymaschalon megalanthum (Merr.) Jing Wang \& R.M.K. Saunders, Philippines, Luzon, Ramos \& Edaño 46641, UC: JQ768596*, JQ768596*, JQ768637*, JQ768678*, JQ768718*. Dasymaschalon oblongatum Merr., Philippines, Luzon, Merrill 9703, NY: JQ768559*, JQ768597*, JQ768638*, JQ768679*, JQ768719*. Dasymaschalon obtusipetalum Jing Wang, Chalermglin \& R.M.K. Saunders, Thailand, Chiang Rai, Keßler 3271, L: JQ768560*, JQ768598*, JQ768639*, JQ768680*, JQ768720*. Dasymaschalon robinsonii Ast, Vietnam, Annam, Poilane 6132, P: JQ768561*, -, JQ768640*, JQ768681*, JQ768721*. Dasymaschalon rostratum Merr. \& Chun, China, Guangdong, Wang 0626, HKU: JQ768562*, JQ768599*, JQ768641*, JQ768682*, JQ768722*. Dasymaschalon sootepense Craib, Thailand, Chiang Mai, Kerr 1364, L: JQ768563*, JQ768600*, JQ768642*, JQ768683*, JQ768723*. Dasymaschalon tibetense X.L. Hou, China, Tibet, Tibet team 74-4348, KUN: JQ768564*, JQ768601*, JQ768643*, JQ768684*, JQ768724*. Dasymaschalon trichophorum Merr., China, Guangdong, Wang 63, HKU: JQ768565*, JQ768602*, JQ768644*, JQ768685*, JQ768725*. Dasymaschalon wallichii (Hook. f. \& Thomson) Jing Wang \& R.M.K. Saunders, Malaysia, Johore, David 257, P: JQ768566*,-, JQ768645*, JQ768686*, JQ768726*. Desmos chinensis Lour., China, Hong Kong, Pang N2, HKU: JQ768567*, JQ768603*, JQ768646*, JQ768687*, JQ768727*. Desmos cochinchinensis Lour., China, Yunnan, Wang 0612, HKU: JQ768568*, JQ768604*, JQ768647*, JQ768688*, JQ768728*. Desmos dinhensis (Finet \& Gagnep.) Merr., Vietnam, Meinke \& Chalermglin MEI013, L: JQ768569*, JQ768605*, JQ768648*, -, JQ768729*. Desmos dumosus (Roxb.) Saff., China, Yunnan, Wang 068, HKU: JQ768570*, JQ768606*, JQ768649*, JQ768689*, JQ768730*. Desmos elegans (Thwaites) Saff., Sri Lanka, Galle, Kostermans 24761, L: JQ768571*, -, JQ768650*, JQ768690*, JQ768731*. Desmos goezeanus (F. Muell.) Jessup, Australia, Queensland, Ford \& Cinelli 04780, BRI: JQ768572*, JQ768607*, JQ768651*, JQ768691*, JQ768732*. Desmos sp., India, Sasidharan 3132, L: JQ768573*, -, JQ768652*, JQ768692*, JQ768733*. Desmos wardianus (Bailey) Jessup, Australia, Queensland, Sankowsky 2664, BRI: JQ768574*, JQ768608*, JQ768653*, JQ768693*, JQ768734*. Fissistigma polyanthoides (A. DC.) Merr., Thailand, Keßler 3232, WAG: JQ768575*, JQ768609*, JQ768654*, JQ768694*, JQ768735*. Friesodielsia biglandulosa (Blume) Steenis, Indonesia, Slik 3809, L: -, JQ768610*, JQ768655*, -, JQ768736*. Friesodielsia cuneiformis (Blume) Steenis, Indonesia, cultivated at Bogor Botanic Gardens, Ardi 54, HKU: JQ768576*, JQ768611*, -, JQ768695*, JQ768737*. Friesodielsia desmoides (Craib) Steenis, Thailand, Keßler 3189, WAG: JQ768577*, JQ768612*, JQ768656*, JQ768696*, JQ768738*. Friesodielsia enghiana (Diels) Verdc. ex Le Thomas, Gabon, Ogooué-Maritime, Harris 8708, E: JQ768578*, JQ768613*, JQ768657*, JQ768697*, JQ768739*. Friesodielsia obovata (Benth.) Verdc., U.K., cultivated at the Royal Botanic Garden Kew, Chase 40526, K: JQ768579*, JQ768614*, JQ768658*, JQ768698*, JQ768740*. Friesodielsia sp., Gabon, Ogooué-Ivindo, Wieringa 
Appendix. Continued.

\& al. 3605, WAG: JQ768580*, JQ768615*, JQ768659*, JQ768699*, JQ768741*. Hexalobus salicifolius Eng1.: EU169694, EU169714, EU169738, EU169761, EU169783. Isolona campanulata Engl. \& Diels: AY238963, EF179301, DQ125127, AY238954, AY231287 and AY238947. Mitrella kentii (Blume) Miq., Malaysia, Gardette 2239, L: FJ743751, JQ768616*, FJ743789, AY841633, AY841711. Monanthotaxis buchananii (Engl.) Verdc., Kenya, Coast, Robertson 7544, WAG: JQ768581*, JQ768617*, JQ768660*, JQ768700*, JQ768742*. Monanthotaxis congoensis Baill., Netherlands, cultivated at Utrecht Botanic Garden, Chatrou 489, U: JQ768582*, JQ768618*, JQ768661*, JQ768701*, JQ768743*. Monanthotaxis fornicata (Baill.) Verdc., Tanzania, Morogoro, Couvreur 89, WAG: JQ768583*, JQ768619*, JQ768662*, JQ768702*, JQ768744*. Monanthotaxis glomerulata (Le Thomas) Verdc., Gabon, Ogooué-Lolo, Sosef 2016, WAG: JQ768584*, JQ768620*, JQ768663*, JQ768703*, JQ768745*. Monanthotaxis schweinfurthii (Engl. \& Diels) Verdc., Gabon, Ogooué-Ivindo, Sosef 2238, WAG: JQ768585*, JQ768621*, JQ768664*, JQ768704*, JQ768746*. Monanthotaxis trichocarpa (Engl. \& Diels) Verdc., Tanzania, Tanga, Couvreur 14, WAG: JQ768586*, JQ768622*, JQ768665*, JQ768705*, JQ768747*. Monanthotaxis whytei (Stapf) Verdc.: EF179278, EF179304, EF179315, AY841635, AY841713. Sanrafaelia ruffonammari Verdc.: EU169703, EU169724, EU169746, EU169768, EU169790. Sphaerocoryne gracilis (Engl. \& Diels) Verdc., Kenya, Coast, Robertson 7554, WAG: EU169688, JQ768623*, EU169732, EU169755, EU169777. Sphaerocoryne sp., Thailand, cultivated in the private collection of P. Chalermglin (Bangkok), Saunders 07/4, HKU: AY518878, JQ768624*, FJ743788, AY319071, AY319185. Toussaintia orientalis Verdc.: EU169689, EU169710, EU169733, EU169756, EU169778. Uvaria lucida Benth.: AY238966, EF179310, AY841440, AY238957, AY231290 and AY238950. Uvariodendron molundense (Diels) R.E. Fr.: EU169707, EU169727, EU169750, EU169772, EU169794. 